\title{
Adsorptive Removal from Aqueous Solution of Cr(VI) by Green Moringa Tea Leaves Biomass
}

\author{
Candice C. Timbo ${ }^{1}$, Martha Kandawa-Schulz ${ }^{1}$, Marta Amuanyena ${ }^{2}$, Habauka M. Kwaambwa ${ }^{2 *}$ \\ ${ }^{1}$ Department of Chemistry and Biochemistry, University of Namibia, Windhoek, Namibia \\ ${ }^{2}$ Faculty of Health and Applied Sciences, Namibia University of Science and Technology, Windhoek, Namibia \\ Email: ${ }^{*} h k w a a m b w a @ n u s t . n a$
}

How to cite this paper: Timbo, C.C., Kandawa-Schulz, M., Amuanyena, M. and Kwaambwa, H.M. (2017) Adsorptive Removal from Aqueous Solution of $\mathrm{Cr}(\mathrm{VI})$ by Green Moringa Tea Leaves Biomass. Journal of Encapsulation and Adsorption Sciences, 7, 108-119.

https://doi.org/10.4236/jeas.2017.72008

Received: January 18, 2017

Accepted: June 25, 2017

Published: June 28, 2017

Copyright $\odot 2017$ by authors and Scientific Research Publishing Inc. This work is licensed under the Creative Commons Attribution International License (CC BY 4.0).

http://creativecommons.org/licenses/by/4.0/

\begin{abstract}
Hexavalent chromium, $\mathrm{Cr}(\mathrm{VI})$, is a toxic metal present in industrial effluents. The study was carried to test the use of green Moringa leaves biomass as adsorbent for $\mathrm{Cr}(\mathrm{VI})$ from aqueous solutions. Batch adsorption method was used and the concentration of $\mathrm{Cr}(\mathrm{VI})$ measured using an ultraviolet-visible (UV-Vis) spectrophotometry. The effects of the adsorption contact time, adsorbent dosage, $\mathrm{pH}$, initial adsorbate concentration and temperature were studied. Results show maximum removal of $\mathrm{Cr}(\mathrm{VI})$ of $99 \% \pm 1 \%$, with maximum adsorption capacity of $33.9 \mathrm{mg} / \mathrm{g}$ at a $\mathrm{pH}$ 2, 60 minutes contact time and $100 \mathrm{mg} / \mathrm{l}$ initial Cr(IV) concentration. The Langmuir and Freundlich adsorption isotherm models were used to fit the experimental data. The data showed that adsorption on green Moringa oleifera leaves tea biomass fitted well to Freundlich isotherm $\left(r^{2}=0.9432\right)$ compared to the Langmuir isotherm $\left(r^{2}=\right.$ 0.9122). M. oleifera leaves biomass can be used in water purification systems. The sludge of $M$. oleifera leaves is biodegradable, cost effective and environmentally friendly and therefore attractive in hexavalent chromium removal in water.
\end{abstract}

\section{Keywords}

Adsorbent, Adsorption Isotherm, Heavy Metals, Hexavalent Chromium, Moringa oleifera

\section{Introduction}

Effluents from industrial activities are normally the culprits in pollution of water bodies by heavy metals such as cadmium $(\mathrm{Cd})$, chromium $(\mathrm{Cr})$, lead $(\mathrm{Pb})$, mercury $(\mathrm{Hg})$, nickel $(\mathrm{Ni})$, etc. Heavy metals are non-biodegradable, carcinogenetic and bioaccumulate and hence they have been implicated in causing a wide range of diseases and disorders. Hexavalent chromium, $\mathrm{Cr}(\mathrm{VI})$, is one of the heavy 
metals that has been associated with health problems which include digestive tract and lungs cancer, diarrhea, nausea, vomiting, to mention but a few, $\mathrm{Cr}(\mathrm{VI})$, just like many other heavy metals, is discharged to the environment from industries such as electroplating, leather tanning and paints and pigments. Since $\mathrm{Cr}(\mathrm{VI})$ has carcinogenic, mutagenic and teratogenic properties, discharge from such industries has the potential to contaminate water bodies.

As result of the health problems associated with heavy metal pollution in water, there are several methods are being used to remove or recover them from industrial effluents. The techniques normally used include chemical precipitation, coagulation, flotation, ion-exchange, reverse osmosis, electrochemical treatments, cementation, membrane separation, hyperfiltration, evaporation, oxidation and solvent extraction [1]. Secondly, there are several disadvantages associated these techniques. Firstly, there is an issue of cost of the reagents and energy requirements which are serious problem for developing countries. Secondly, the operational costs involving disposal of toxic sludge generated because some of these techniques, such as precipitation, do not remove the heavy metals to acceptable limits and, in fact, produce waste that is difficult to treat. Techniques like ion exchange, although effective, require costly adsorbents materials for the removal of heavy metals from dilute aqueous streams. In view of the above-mentioned drawbacks, the use of low-cost materials of biological origin as adsorbents are being advocated by many researchers because they provide an economic solution through reduction of exorbitant costs for water and wastewater treatment. Many researchers are using these materials to study their adsorption properties and thus determine their potential in water and wastewater treatment. Adsorption is process by which impurities are selectively transferred from the fluid phase to the surface of particles suspended. The advantage is adsorption over other methods is that it requires a simple design with sludge free environment and hence can involve low investment in terms of both initial cost and land required.

The study was aimed at using $M$. oleifera tea leaf biomass waste as a possible sustainable technology to a global problem of water and wastewater treatment. M. oleifera is often referred to a multipurpose tree because it has been found to have nutritional, antimicrobial, medicinal, industrial and water treatment properties. For instance, Moringa leaves have been used as natural antihelmintic, antioxidant, antibiotic, detoxifer, and immune builders in some countries for the treatment of malnutrition and malaria. Because of the health and nutritional benefits of the leaves, there is an increase in the number of Moringa products on the market such as Moringa tea. As result, more and more people are buying Moringa products and therefore the cultivation of Moringa and consumption of Moringa tea will grow worldwide especially southern Africa [2]. The aim of this study is to find out the effectiveness of green $M$. oleifera tea leaf biomass waste as an adsorbent for the removal of $\mathrm{Cr}(\mathrm{VI})$ from water. Contact time, adsorbent dosage, $\mathrm{pH}$, initial $\mathrm{Cr}(\mathrm{VI})$ concentration and temperature were the parameters used to study the adsorption behavior of $\mathrm{Cr}(\mathrm{VI})$ on $M$. 
oleifera tea leaf biomass.

\section{Materials and Methods}

\subsection{Preparation of Adsorbent}

Green $M$. oleifera leaves were obtained from a tree in Cimbebasia, Windhoek. The leaves were washed and air dried in an open space away from sunlight. After drying, the leaves were washed several times with hot to boiling distilled water until a colourless filtrate was obtained. The decolourized Moringa leaves were then dried in an oven at $105^{\circ} \mathrm{C}$. After drying, the leaves were ground to a fine powder using a mortar and pestle and then sieved to size range $250-500 \mu \mathrm{m}$. Crushed leaves powder was then stored in sealed bottles at room temperature for the adsorption studies.

\subsection{Batch Adsorption Studies}

A stock solution which contains $1000 \mathrm{mg} / \mathrm{l}$ of $\mathrm{Cr}(\mathrm{VI})$ was prepared using analytical grade potassium dichromate $\left(\mathrm{K}_{2} \mathrm{Cr}_{2} \mathrm{O}_{7}\right)$ in distilled water. The adsorption experiments were carried out in $30 \mathrm{ml}$ test tubes with the Moringa leaves adsorbent and the $\mathrm{Cr}(\mathrm{VI})$ solution. The concentration of chromium was then determined using an ultraviolet-visible spectrophotometer at $350 \mathrm{~nm}$. The batch adsorption studies were then carried out by varying the experimental conditions, namely contact time, adsorbent dosage, initial concentration of chromium and $\mathrm{pH}$. The percentage removal of $\mathrm{Cr}(\mathrm{VI})$ and adsorption capacity of the adsorbent for each concentration of $\mathrm{Cr}(\mathrm{VI})$ ions at equilibrium, $q_{e}$, were calculated, respectively, using Equations (1) and (2):

$$
\begin{gathered}
\text { \%Removal }=\frac{\left(C_{o}-C_{f}\right)}{C_{o}} \times 100 \\
q_{e}(\mathrm{mg} / \mathrm{g})=\frac{\left(C_{o}-C_{f}\right) V}{m}
\end{gathered}
$$

where $C_{o}$ is initial chromium concentration, $C_{f}$ is final concentration, i.e. after treatment, $V$ is the volume of solution (l) and $m$ is the mass of adsorbent. To eliminate any instrumental error, the metal ion concentration before and after adding adsorbent was analyzed via a calibration curve with concentrations ranging from 10 to $100 \mathrm{mg} / \mathrm{l}$ prepared from the stock solution of $\mathrm{K}_{2} \mathrm{Cr}_{2} \mathrm{O}_{7}$. The results from the calibration curve (not shown here) indicated that absorbance increases linearly with increase in concentration. The correlation coefficient value, $r^{2}$, calculated from the linear calibration curve data gave a value of 0.997 which shows that there is a significant linear relationship between the absorbance and the concentration.

To make the mixtures, a known amount of adsorbent was added to a solution of known metal ion concentration, and the resulting mixture was shaken using a mechanical shaker (Stuart Scientific). The mixture was then centrifuged and filtered using Whatman paper No. 1 filter paper. The concentration on metal ion in the filtrate, i.e. concentration of the un adsorbed metal ion in a solution, was 
the determined. The effects of contact time, adsorbent dosage, $\mathrm{pH}$, initial $\mathrm{Cr}(\mathrm{VI})$ concentration and temperature were studied. To adjust $\mathrm{pH}$ of the mixtures as required, $0.1 \mathrm{M} \mathrm{HCl}$ and $0.1 \mathrm{M} \mathrm{NaOH}$ were used. The data reported here represent the mean of the two independent experiments (i.e. each experiment done in duplicate). The difference between two replicate experiments was less than $10 \%$ in all cases.

The Langmuir and Freundlich isotherm models were used to test the adsorption process of $\mathrm{Cr}(\mathrm{VI})$ on the Moringa tea leaf biomass. The linear forms of Langmuir and Freundlich equations are given in Equation (3) and (4), respectively [3] [4] [5]:

$$
\begin{aligned}
\frac{C_{e}}{q_{e}} & =\frac{1}{q_{m} b}+\frac{1}{q_{m}} C_{e} \\
\ln q_{e} & =\ln K_{F}+\frac{1}{n} \ln C_{e}
\end{aligned}
$$

In Equations (3) and (4), $C_{e}$ is the equilibrium concentration of adsorbate $(\mathrm{mg} / \mathrm{L})$ and $q_{e}$ is the amount in grams of $\mathrm{Cr}(\mathrm{VI})$ adsorbed per gram of adsorbent at equilibrium, $q_{m}$ and $b$ are Langmuir constants related to adsorption capacity and rate of adsorption, respectively. The values of $q_{m}$ and $b$ (with typical of units $\mathrm{mg} / \mathrm{g}$ and $1 / \mathrm{mg}$, respectively) are calculated from the slope and intercept of the linear Langmuir plot of $C_{e} / q_{e}$ versus $C_{e^{*}}$ In the Freundlich equation, $K_{F}$ and $n$ are the constants incorporating all factors affecting the adsorption process (adsorption capacity and intensity). The values of the constants $K_{F}$ and $n$ are calculated from the intercept and slope of the Freundlich linear plot.

\section{Results and Discussion}

\subsection{Effect of Contact Time}

The contact time required to reach adsorption equilibrium of $\mathrm{Cr}(\mathrm{VI})$ ions was studied between 10 to 100 minutes by carrying out the experiments at constant initial metal ion concentrations $(100 \mathrm{mg} / \mathrm{l})$, adsorbent dosage $(0.4 \mathrm{~g} / 50 \mathrm{ml})$, neutral $\mathrm{pH}$, stirring speed $(165 \mathrm{rpm})$ and room temperature. The results of the effect contact time on removal of $\mathrm{Cr}(\mathrm{VI})$ under these conditions are shown in Figure 1. As the contact time increased, the amount of $\mathrm{Cr}(\mathrm{VI})$ adsorbed also increased. After 60 minutes, the solution attained equilibrium. This result is in agreement with other adsorption studies on similar type of materials whereby the equilibrium time was attained within two hours [3].

The progress of adsorption process can be described in two distinct stages. Typically, the first stage is involves a rapid adsorption, whereas the next stage is a slower adsorption process. Veena Devi et al. [4] explained that the rapid adsorption stage is as a result of a large numbers of vacant sites that are present, which ultimately leads to fast adsorption. There is then the slowing down of the process which can be attributed to the decrease in the heat of adsorption. The heat of adsorption is decreased because it is affected by the increase in work function (work done to overcome repulsion to the surface) with increase is surface 


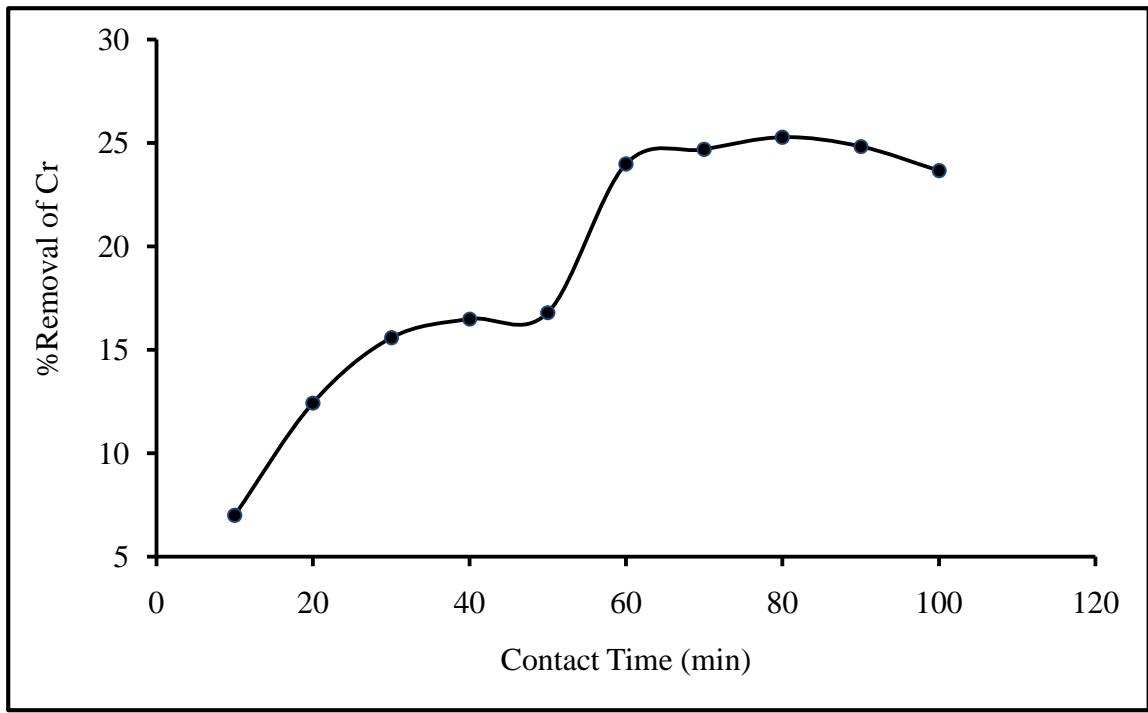

Figure 1. Effect of contact time of the $\mathrm{Cr}(\mathrm{VI})$ adsorption on green tea biomass (Dosage = $0.4 \mathrm{~g})$.

coverage. The interaction between adsorbed species also results in less heat of adsorption being given out as more adsorbate molecules are adsorbed.

\subsection{Effect of Solution $\mathrm{pH}$}

Solution $\mathrm{pH}$ is one of the important factors controlling the process of adsorption of metal ions as it affects the surface charge density of the adsorbent [5] [6]. It is known that the $\mathrm{pH}$ dependence of metal adsorption is largely related to the surface functional groups in the biosorbents and metal solution chemistry [7].

A $\mathrm{pH}$ range of 1 - 11 was used to study the effect $\mathrm{pH}$ in adsorption experiments were carried out in the $\mathrm{pH}$ range of $1-11$. As mentioned earlier, the adjustment was done using $0.1 \mathrm{M} \mathrm{HCl}$ and $0.1 \mathrm{M} \mathrm{NaOH}$ while keeping all other parameters constant, i.e. chromium concentration $(100 \mathrm{mg} / \mathrm{l})$, adsorbent dosage $(0.4 \mathrm{~g} / 50 \mathrm{ml})$, stirring speed $(165 \mathrm{rpm})$, contact time (60 minutes), and room temperature.

Figure 2 shows that as the $\mathrm{pH}$ was increased, the percentage removal of $\mathrm{Cr}(\mathrm{VI})$ was decreased from about $97 \%$ at $\mathrm{pH} 2$ to as low as $9.45 \%$ at $\mathrm{pH}$. The maximum adsorption took place at lower $\mathrm{pH}$ and $\mathrm{pH} 2$ was taken to be optimum value. Adsorption of $\mathrm{Cr}(\mathrm{VI})$ is clearly a function of solution $\mathrm{pH}$ and one of the species $\mathrm{H}_{2} \mathrm{CrO}_{4}, \mathrm{HCrO}_{4}^{-}, \mathrm{Cr}_{2} \mathrm{O}_{7}^{2-}$ or $\mathrm{CrO}_{4}^{2-}$ will be dominant depending on the $\mathrm{pH}$ [5]. The dominant ionic form of $\mathrm{Cr}(\mathrm{VI})$ at $\mathrm{pH} 2$ is $\mathrm{HCrO}_{4}^{-}$while $\mathrm{CrO}_{4}^{2-}$ is dominant in the range of $\mathrm{pH}>7$ based on the $\mathrm{pK}_{\mathrm{a}}$ values [8] [9].

At acidic $\mathrm{pH}(\sim 2)$, in which higher level $\mathrm{Cr}(\mathrm{VI})$ elimination was observed, adsorbent surface is highly protonated, facilitating $\mathrm{HCrO}_{4}^{-}$anion removal as a result of electrostatic interaction based adsorption. However, surface protonation decreases when $\mathrm{pH}$ is increased. There is strong competition between $\mathrm{CrO}_{4}^{2-}$ and $\mathrm{OH}^{-}$species present at high $\mathrm{pH}$ values. Thus, the number of positive sites on adsorbent surface becomes reduced at high $\mathrm{pH}$, showing a decrease in $\mathrm{Cr}(\mathrm{VI})$ removal capacity. 


\subsection{Effect of Adsorbent Dosage}

The effect of adsorbent dosage on the adsorption of $\mathrm{Cr}(\mathrm{VI})$ is shown in Figure 3. Using $100 \mathrm{mg} / \mathrm{l}$ of $\mathrm{Cr}(\mathrm{VI})$, a fixed temperature $\left(60^{\circ} \mathrm{C}\right)$, optimum $\mathrm{pH} 2$ and 60 minutes contact time, the solutions were agitated at $165 \mathrm{rpm}$ with different Moringa dosages ranging from $0.05 \mathrm{~g}$ to $1.0 \mathrm{~g}$ in $50 \mathrm{ml}$.

The results show that $\mathrm{Cr}(\mathrm{VI})$ removal efficiency increases with increase in adsorbent dosage until it becomes constant (i.e. optimum percentage removal of $99 \% \pm 1 \%$ ) at around $0.5 \mathrm{~g}$ of the adsorbent. Jeyaseelan and Gupta [8] observed similar results with the removal efficiency reaching a constant value at $0.8 \mathrm{~g} / 50$ $\mathrm{ml}$ adsorbent dosage of green tea leaves of Camellia sinensis plant species. The results obtained obviously follow such a trend due to more adsorption sites being available with the as amount of adsorbent increases. Since adsorption sites adsorbent particles increase, it would be more probable for $\mathrm{HCrO}_{4}^{-}$and $\mathrm{CrO}_{4}^{2-}$ ions to be adsorbed and thus adsorption efficiency should also increase as stated

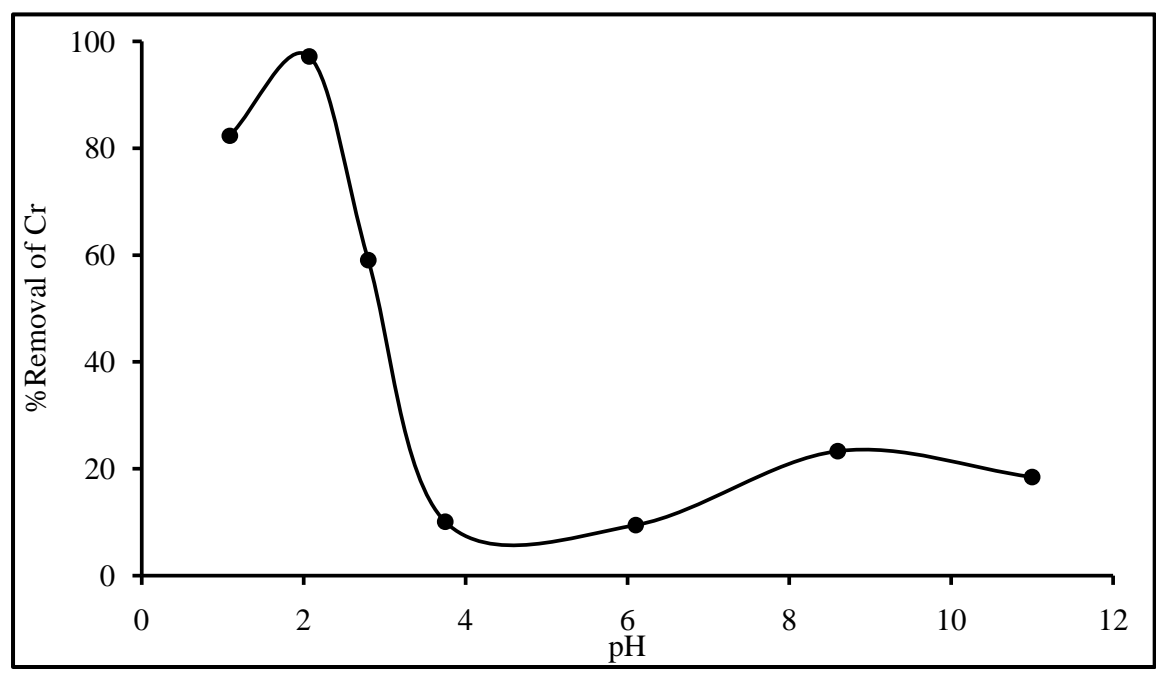

Figure 2. Effect of $\mathrm{pH}$ on $\mathrm{Cr}(\mathrm{VI})$ removal.

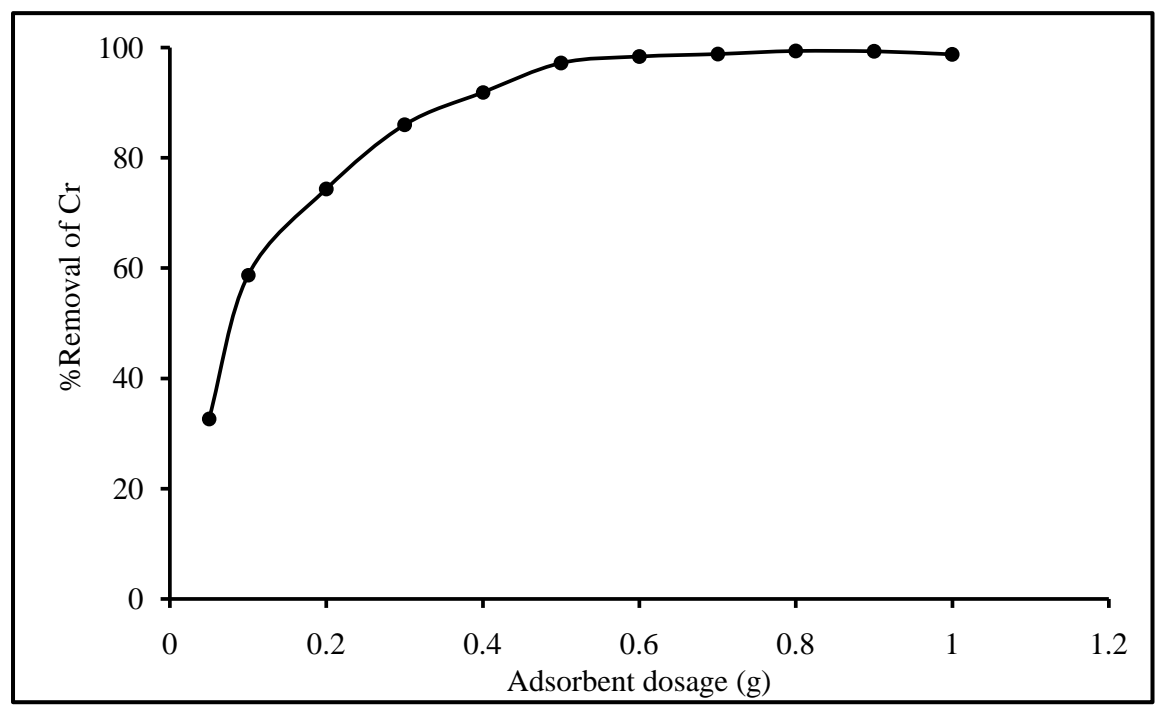

Figure 3. Effect of adsorbent dosage on adsorption of $\mathrm{Cr}(\mathrm{VI})$. 
articulated by Bansal et al., [8]. In this particular case, the concentration of the $\mathrm{Cr}(\mathrm{VI})$ ions is constant and therefore increasing the adsorbent dosage increases the available adsorption surface area. The limiting constant maximum removal capacity could be explained from the fact that all adsorbents have a finite number of active sites which should become saturated at some adsorbate concentration.

\subsection{Effect of Initial Metal Ion Concentration}

A range of concentrations varying from $10 \mathrm{mg} / \mathrm{l}$ to $150 \mathrm{mg} / \mathrm{l}$ of $\mathrm{Cr}(\mathrm{VI})$ were taken, while keeping the dosage, $\mathrm{pH}$, temperature and contact time fixed. It was observed that the removal of $\mathrm{Cr}(\mathrm{VI})$ is dependent on the initial concentration. Figure 4 shows that adsorption is higher at lower concentrations, i.e. increasing initial $\mathrm{Cr}(\mathrm{VI})$ concentration showed a decrease in metal removal. Changing the initial concentration of $\mathrm{Cr}(\mathrm{VI})$ in solution from $10-150 \mathrm{mg} / \mathrm{l}$ caused the percent removal to decrease from $75 \%$ to $8 \%$. At low concentration, the metal ions interact with the binding sites, and result in maximum adsorption. This is because at low concentration, the ratio of available surface to the initial $\mathrm{Cr}(\mathrm{VI})$ concentration is larger, so the removal is higher. Therefore, at low initial metal ion concentrations, the removal capacity is higher. However, in the case of higher concentrations, this ratio is low and hence the percentage removal is also lesser. As the concentration increases, the metal ions start looking for free binding sites, and due to a lack of binding sites for complexation, the adsorption reduces [10]. In other words, when metal ion concentrations are increased, binding sites become saturated more quickly since the amount of biomass concentration remains constant.

\subsection{Effect of Temperature}

Adsorption of $\mathrm{Cr}(\mathrm{VI})$ on $M$. oleifera leaf biomass was studied using six different temperatures $\left(25^{\circ} \mathrm{C}, 30^{\circ} \mathrm{C}, 40^{\circ} \mathrm{C}, 50^{\circ} \mathrm{C}, 60^{\circ} \mathrm{C}\right.$ and $\left.70^{\circ} \mathrm{C}\right)$ at fixed $\mathrm{pH} 2$, chromium

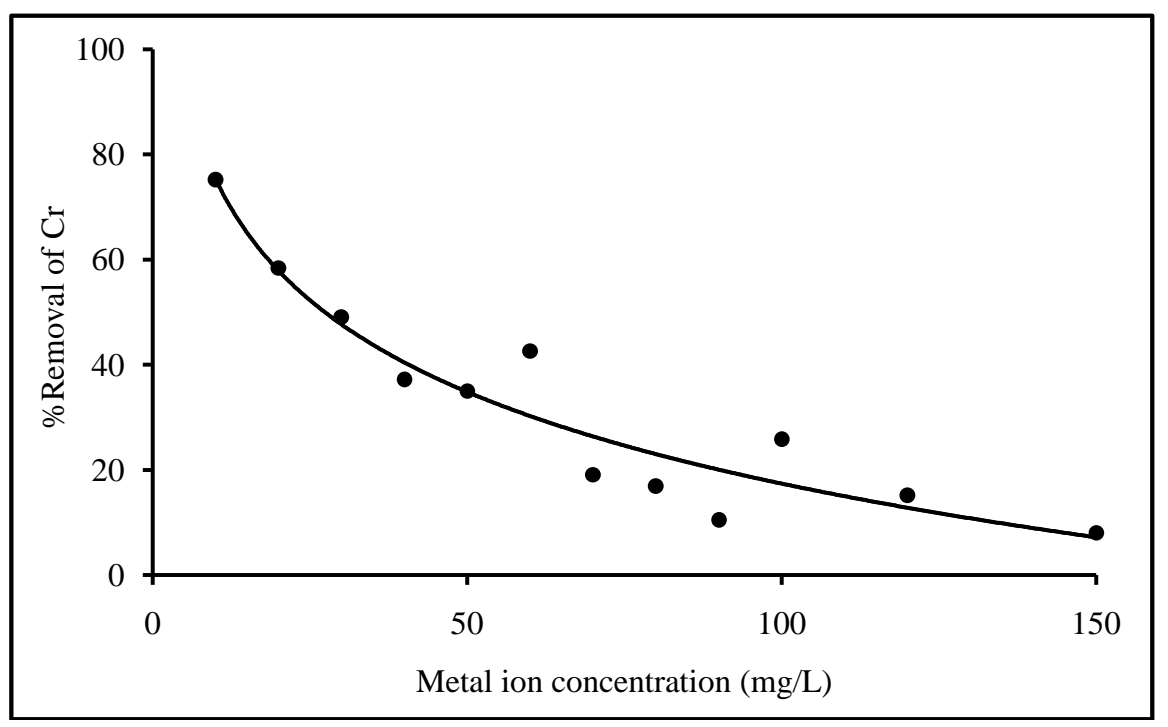

Figure 4. Effect of initial concentration removal of $\mathrm{Cr}(\mathrm{VI})$. 
concentration $(100 \mathrm{mg} / \mathrm{L})$, adsorbent dosage $(0.4 \mathrm{~g} / 50 \mathrm{ml})$, stirring speed (165 $\mathrm{rpm})$ and contact time (60 minutes). Figure 5 shows the effect of temperature on the removal efficiency. Generally in the temperature range used, the percent removal of $\mathrm{Cr}(\mathrm{VI})$ increases from $84 \%$ at $25^{\circ} \mathrm{C}$ reaching a maximum of $98 \%$ at $60^{\circ} \mathrm{C}$. Adsorption efficiency seems to decrease at temperatures higher than $60^{\circ} \mathrm{C}$. The increase in sorption capacity of the biosorbent is attributed to the enlargement of pore size and activation of the sorbent surface with rise in temperature [11]. It has been stated that a further rise in temperature increases the thermal motion of the metal ions and reduces the swelling effect in biosorbent, thus, enabling the metal ions to penetrate further [12] [13]. Similar results of optimal temperature have been observed for $\mathrm{Cr}(\mathrm{VI})$ adsorption with activated carbon [14]. The decrease in adsorption with rise in temperature may be due to desorption caused by the existing thermal energy.

\subsection{Adsorption Isotherms}

Langmuir and Freundlich adsorption isotherms were obtained and are given in Figure 6 and Figure 7, respectively, whereas the resulting corresponding maximum adsorption capacities and regression constants, $r^{2}$, are tabulated in Table 1. The $r^{2}$ value which is close to 1 indicates a good fit to given adsorption model. The adsorption of $\mathrm{Cr}(\mathrm{VI})$ on $M$. oleifera leaves tea biomass gives a better fit of the Freundlich isotherm in comparison to the Langmuir isotherm.

The essential feature of the Langmuir isotherm can be expressed in terms of separation factor $\left(R_{L}\right)$ which is a dimensionless constant also referred to equilibrium parameter. $R_{L}$ can be calculated by using equation:

$$
R_{L}=\frac{1}{1+b C_{o}}
$$

where $C_{o}$ is the initial adsorbate concentration $(\mathrm{mg} / \mathrm{L})$ and $b$ can be obtained from Langmuir plot of $C_{e} / q_{e}$ versus $C_{e}$ and the constant is related to the energy

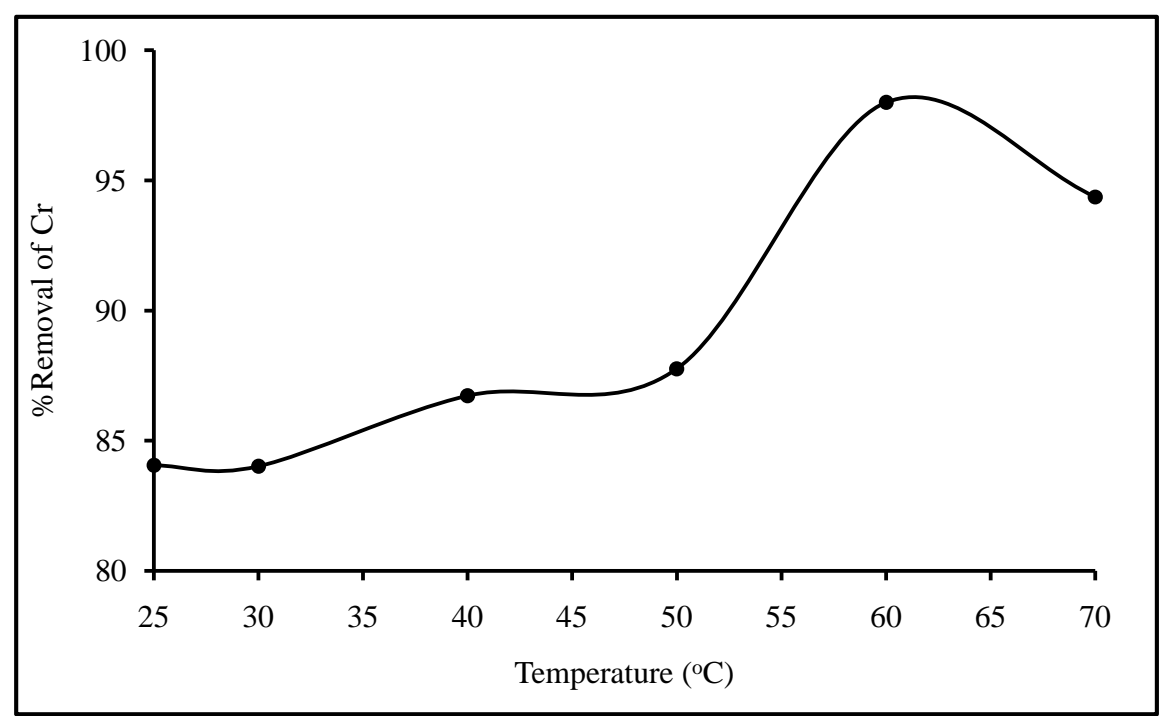

Figure 5. Effect of temperature on $\mathrm{Cr}(\mathrm{VI})$ removal. 


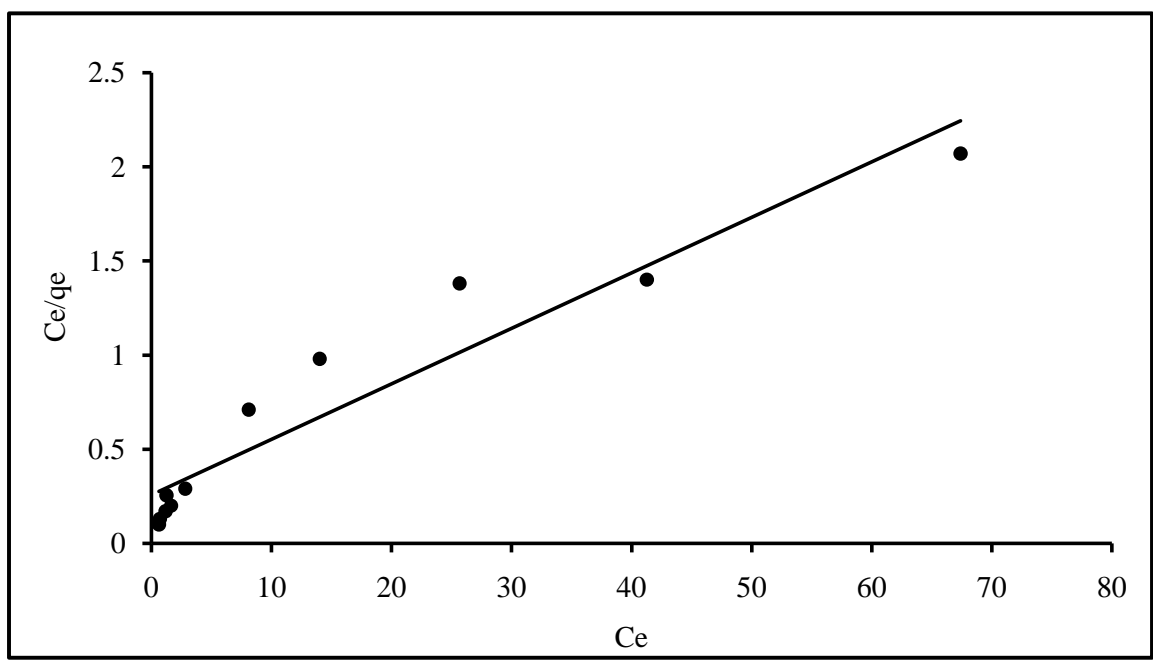

Figure 6. Linear Langmuir isotherm for adsorption of $\mathrm{Cr}(\mathrm{VI})$.

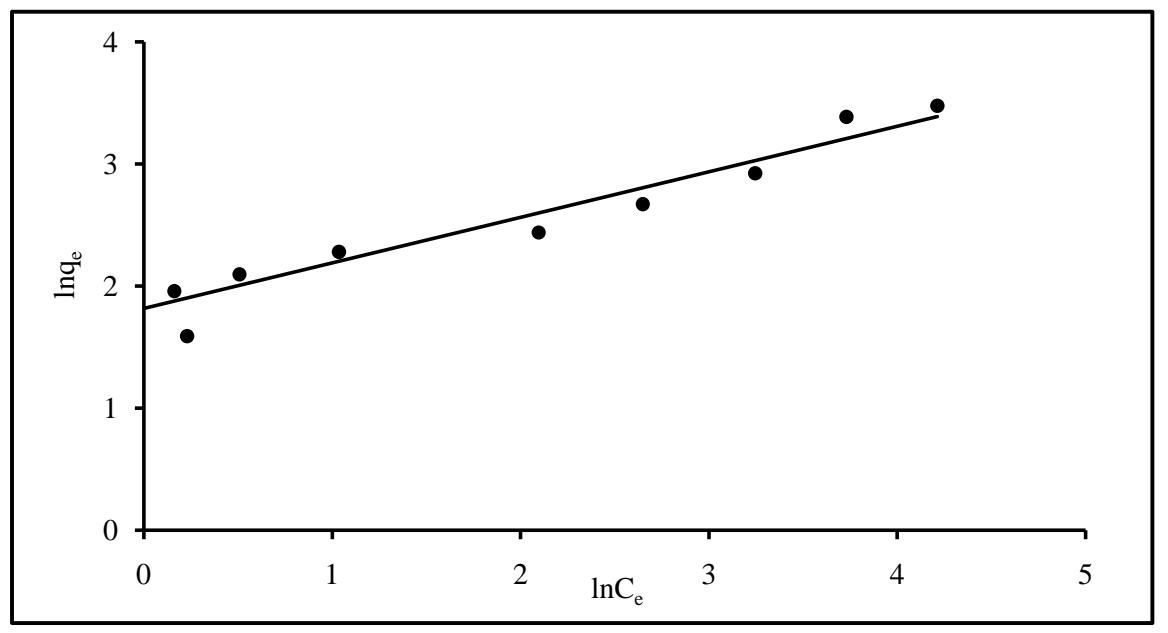

Figure 7. Linear Freundlich isotherm for adsorption $\mathrm{Cr}(\mathrm{VI})$.

Table 1. Langmuir and Freundlich isotherm constants for the adsorption $\mathrm{Cr}(\mathrm{VI})$ on Moringa tea leaf biomass.

\begin{tabular}{cccc}
\hline Langmuir Isotherm & \multicolumn{3}{c}{ Freundlich Isotherm } \\
\hline Slope $\left(=1 / q_{m}\right)$ & 0.0295 & Slope $(=1 / n)$ & 0.373 \\
Intercept $\left(=1 / q_{m} b\right)$ & 0.2573 & Intercept $\left(=\ln K_{F}\right)$ & 1.812 \\
$r^{2}$ & 0.9122 & $r^{2}$ & 0.9432 \\
$q_{m}(\mathrm{mg} / \mathrm{g})$ & 33.9 & $K_{F}(\mathrm{mg} / \mathrm{mg})$ & 6.15 \\
$b(\mathrm{l} / \mathrm{mg})$ & 0.115 & $n(1 / \mathrm{mg})$ & 2.68 \\
\hline
\end{tabular}

of adsorption. The separation factor, $R_{L}$, the isotherm shape as unfavorable adsorption is when $R_{L}>1$, linear for $R_{L}=1$, favorable when $0<R_{L}<1$ and irreversible when $R_{L}=0$.

In this study, the value of $R_{L}$ was found to be 0.00862 . From the result, it is evident that the value of $R_{L}$ on removal of chromium using Moringa tea leaves biomass as adsorbent lies between 0 and 1 and hence, adsorption of the adsor- 
bate seems to be favorable.

In the case of the Freundlich isotherm, $K_{F}$ and $n$ are constants at a particular temperature and for a particular adsorbent and adsorbate. The magnitude of the exponent, $1 / n$, is a heterogeneity parameter or gives an indication of the favorability of adsorption; the smaller $1 / n$, the greater the expected heterogeneity. If $n$ lies in the range $1-10$, it indicates a favorable sorption process. From the data in Table 1 , the value of $1 / n=0.373$ and hence $n=2.68$, indicating that the sorption of $\mathrm{Cr}(\mathrm{VI})$ on to Moringa tea leaf biomass is favorable.

\section{Conclusions}

The study showed the enormous potential of green Moringa tea leaves biomass for $\mathrm{Cr}(\mathrm{VI})$ species removal found in water and wastewater. The following conclusions are drawn from the above results:

- Adsorbent prepared from Moringa leaves biomass could be used for the removal of $\mathrm{Cr}(\mathrm{VI})$ from aqueous solutions. Adsorption of $\mathrm{Cr}(\mathrm{VI})$ on Moringa tea leaf biomass yielded maximum adsorption capacity of $33.9 \mathrm{mg} / \mathrm{g}$ at solution $\mathrm{pH}$ 2. In comparison to other adsorbents such as the ones shown in $\mathrm{Ta}$ ble 2, Moringa leaves biomass has comparable or higher adsorption capacity.

- The equilibrium time for the adsorption of $\mathrm{Cr}(\mathrm{VI})$ on the adsorbent prepared from Moringa tea leaf biomass in the present study from aqueous solutions is found to be 60 minutes.

- The percentage removal of $\mathrm{Cr}(\mathrm{VI})$ using optimum conditions, i.e. $\mathrm{pH} 2$, contact time of 60 minutes, a temperature of $60^{\circ} \mathrm{C}$ and a dosage of $0.5 \mathrm{~g}$, was found to be $99 \% \pm 1 \%$ using initial concentration of $100 \mathrm{mg} / \mathrm{l}$.

- Increase of adsorbent dosage causes an increase in the removal of $\mathrm{Cr}(\mathrm{VI})$.

- The adsorption process of $\mathrm{Cr}(\mathrm{VI})$ can be described by Langmuir and Freundlich isotherm models. However, Freundlich isotherm model shows a better agreement with the equilibrium data.

Table 2. Comparison of adsorbent capacity of various adsorbents.

\begin{tabular}{|c|c|c|c|c|}
\hline Adsorbent & Adsorption capacity, mg/g & Initial $\mathrm{Cr}(\mathrm{VI})$ concentration range, $\mathrm{mg} / \mathrm{l}$ & $\mathrm{pH}$ & Reference \\
\hline M. oleifera leaves biomass & 33.9 & $10-150$ & 2 & This study \\
\hline Euclear schimperi leaves & 3.95 & $5-20$ & 2 & {$[10]$} \\
\hline Acacia albida barks & 2.98 & $2-20$ & 2 & {$[10]$} \\
\hline Neem leaves & 10.4 & $20-200$ & $1-3$ & [15] \\
\hline Orange peel & 19.80 & $10-150$ & 2 & {$[16]$} \\
\hline Neem sawdust & 58.82 & $10-150$ & 2 & {$[16]$} \\
\hline Mango sawdust & 37.73 & $10-150$ & 2 & {$[16]$} \\
\hline Asperigillus niger & 6.97 & $25-100$ & 6 & {$[17]$} \\
\hline Cactus leaves & 7.08 & - & 2 & {$[18]$} \\
\hline Cooked tea dust & 30.39 & $25-125$ & 2 & [19] \\
\hline Camellia sinensis green tea leaves & 34.59 & $5-500$ & 2 & [8] \\
\hline
\end{tabular}


The characterization of the surface of the green Moringa tea leaves biomass by some analytical techniques such as infrared spectroscopy, scanning electron microscopy (SEM), BET surface area, and surface charge by measuring zeta potential may have provided more insight the adsorption mechanism of $\mathrm{Cr}(\mathrm{VI})$.

\section{Acknowledgements}

The authors wish to acknowledge the research funding from NCRST and NRF under the Namibia - South Africa Research Partnership Bilateral Agreement programme.

\section{References}

[1] Fu, F. and Wang, Q.I. (2011) Removal of Heavy Metal Ions from Wastewaters: A Review. Journal of Environmental Management, 92, 407-418. https://doi.org/10.1016/j.jenvman.2010.11.011

[2] Kwaambwa, H.M., Chimuka, L., Kandawa-Schulz, M., Munkombwe, N.M. and Thwala, J.M. (2012) Situational Analysis and Promotion of the Cultivation and Utilisation of the Moringa oleifera Tree in Selected Sub-Saharan Africa Countries. Progress Multi-Disciplinary Research Journal, 4, 9-40.

[3] Vargas-Nieto, C., Carriazo, J.G. and Castillo, E. (2011) A Study of Low-Cost Adsorbent Materials for Removing Cr(VI) from Aqueous Waste Effluent. Ingeniería $E$ Investigación, 31, 154-162.

[4] Veena Devi, B., Jahagirdar, A.A. and Zulfiqar Ahmend, M.N. (2012) Adsorption of Chromium on Activated Carbon Prepared from Coconut Shell. International Journal of Engineering Research and Applications, 2, 364-370.

[5] Venkateswarlu, P., Venkata Ratnam, M., Rao, D. and Rao, M. (2007) Removal of Chromium from an Aqueous Solution Using Azadirachta indica (neem) Leaf Powder as an Adsorbent. International Journal of Physical Sciences, 2, 188-195. http://www.academicjournals.org/IJPS

[6] Bansal, M., Singh, D., Garg, V.K. and Rose, P. (2008) Mechanisms of Cr(Vi) Removal from Synthetic Wastewater by Low Cost Adsorbents. Journal of Environmental Research and Development, 3, 228-243.

[7] Chen, P., Xiong, Z., Luo, J., Lin, J. and Tan, K.L. (2002) Interaction of Hydrogen with Metal Nitrides and Imides. Nature, 420, 302-304. https://doi.org/10.1038/nature01210

[8] Jeyaseelan, C. and Gupta, A. (2016) Green Tea Leaves as a Natural Adsorbent for the Removal of Cr(VI) from Aqueous Solutions. Air, Soil and Water Research, 9, 13-19. https://doi.org/10.4137/ASWR.S35227

[9] Dehghani, M.H., Sanaei, D., Ali, I. and Bhatnagar, A. (2016) Removal of Chromium(VI) from Aqueous Solution Using Treated Waste Newspaper as a Low-Cost Adsorbent: Kinetic Modeling and Isotherm Studies. Journal of Molecular Liquids, 215, 671-679. https://doi.org/10.1016/j.molliq.2015.12.057

[10] Gebrehawaria, G., Hussen, A. and Rao, V.M. (2015) Removal of Hexavalent Chromium from Aqueous Solutions Using Barks of Acacia albida and Leaves of Euclea schimperi. International Journal of Environmental Science and Technology, 12, 1569-1580. https://doi.org/10.1007/s13762-014-0530-2

[11] Taheryan, P., Shahidi, A. and Najafi Mood, M.H. (2015) Removal Performance Assessment of Chromium (VI) in Solution Using Grape Leaves Powder and Carbon as Adsorbent. International Journal of Research Studies in Agricultural Sciences, 1, 21- 
28.

[12] Mckay, G., Blair, H.S. and Gardener, J.K. (1982) Adsorption of Dyes on Chitin. Equilibrium Studies. Journal of Applied Polymer Science, 27, 3043-3057. https://doi.org/10.1002/app.1982.070270827

[13] Guo, Y.P, Yang, S.F, Yu, K.F, Wang, Z.C. and Xu, H.D. (2002) Adsorption of $\mathrm{Cr}(\mathrm{VI})$ on Micro- and Mesoporous Rice Husk-Based Active Carbon. Materials Chemistry and Physics Journal, 78, 132-137.

[14] Mohanty, S., Bal, B. and Das, A.P. (2014) Adsorption of Hexavalent Chromium onto Activated Carbon. Austin Journal of Biotechnology \& Bioengineering, 1, 5.

[15] Gupta, S. and Babu, B.V. (2006) Adsorption of Cr(VI) by a Low-Cost Adsorbent Prepared from Neem Leaves. Proceedings of National Conference on Environmental Conservation, 1-3, 175-180.

[16] Vinodhini, V. and Das, N. (2010) Relevant Approach to Assess the Performance of Sawdust as Adsorbent of Chromium (VI) Ions from Aqueous Solutions. International Journal of Environmental Science and Technology, 7, 85-92. https://doi.org/10.1007/bf03326120

[17] Munir, K., Yusuf, M., Noreen, Z., Hameed, A., Hafeez, F.Y. and Faryal, R. (2010) Isotherm Studies for Determination of Removal Capacity of Bi-Metal (Ni and $\mathrm{Cr}$ ) Ions by Aspergillus niger. Pakistan Journal of Botany, 42, 593-604.

[18] Dakiky, M., Khamis, M., Manassra, A. and Mereb, M. (2002) Selective Adsorption of Chromium (VI) in Industrial Wastewater Using Low-Cost Abundantly Available Adsorbents. Advances in Environmental Research Journal, 6, 533-540.

[19] Dhanakumar, S., Solaraj, G., Mohanraj, R. and Pattabh, S. (2007) Removal of Cr (VI) from Aqueous Solution by Adsorption Using Cooked Tea Dust. Indian Journal of Science and Technology, 1, 1-6. http://www.indjst.org

\section{Submit or recommend next manuscript to SCIRP and we will provide best} service for you:

Accepting pre-submission inquiries through Email, Facebook, LinkedIn, Twitter, etc. A wide selection of journals (inclusive of 9 subjects, more than 200 journals)

Providing 24-hour high-quality service

User-friendly online submission system

Fair and swift peer-review system

Efficient typesetting and proofreading procedure

Display of the result of downloads and visits, as well as the number of cited articles

Maximum dissemination of your research work

Submit your manuscript at: http://papersubmission.scirp.org/

Or contact jeas@scirp.org 